\title{
Representaçōes da afetividade na literatura afro-brasileira de autoria feminina contemporânea
}

\author{
Representations of affectivity in the contemporary \\ brazilian black women's literature
}

Rodrigo da Rosa Pereira

FURG

DOI: $h t t p: / / d x$. doi.org/10.5902/2176148531669

\begin{abstract}
Resumo: Este trabalho busca investigar diferentes representações das afetividades na literatura afro-brasileira de autoria feminina contemporânea, tomando por base contos publicados na série literária Cadernos Negros. As noções de sororidade e matrifocalidade, bem como da espiritualidade afrodescendente colocam-se relevantes para compreendermos as relações afetivas de solidariedade e cooperação que se estabelecem nas narrativas. Entretanto, verificamos também relações de vulnerabilidade afetivas, vistas como consequências negativas intimamente ligadas ao distanciamento da tradição afrodescendente.
\end{abstract}

Palavras-chave: Literatura afro-brasileira. Autoria feminina. Afetividade.

Abstract: This study aims to discuss the different representations of affectivities in the contemporary Brazilian Black Literature written by women. To do so, some short stories published in the literary series Cadernos Negros are brought to analysis. The notions of sorority and matrifocality, as well as African descendant spirituality are relevant to understand the relationships of solidarity and cooperation that are established in the narratives. Also, affective vulnerability relations are seen as negative consequences closely linked to the distancing of the African descendant traditions.

Keywords: Brazilian black literature. Women writing. Affectivity. 


\section{Considerações iniciais: sororidade, matrifocalidade e a valorização das mulheres negras}

No que diz respeito à dinâmica do afeto na literatura afro-brasileira de autoria feminina, fazem-se relevantes as noções de "sororidade" e "matrifocalidade" para compreendermos a perspectiva diferenciada das escritoras negras. Conforme apresentado por Vânia Vasconcelos (2014), o termo "sororidade"1 vem do latim "sorór" (irmãs), mas não faz parte do português brasileiro, sendo compreendido, de modo geral, como a experiência de afetividades positivas e saudáveis entre as mulheres. Para

Rodrigo da Rosa Pereira a estudiosa, tratam-se de relações peculiares às mulheres afrodescendentes, que formam uma espécie de aliança objetivando a transmissão da memória de tradição da cultura afro-brasileira e o exercício da solidariedade em situações difíceis, em particular aquelas que envolvem os conflitos de gênero e raça; na maioria das vezes, esses conflitos também estão relacionados a questões de classe.

Na mesma direção, Adélia Mathias (2014) defende que "sororidade" carrega em si uma dimensão ética, política e prática do feminismo contemporâneo, que aponta para experiências subjetivas entre mulheres em busca por relações positivas e saudáveis na construção de alianças existencial e política com outras mulheres para contribuir com a eliminação social de todas as formas de opressão e ao apoio mútuo para alcançar o empoderamento vital de cada mulher. Portanto, a compreensão da "sororidade" possui um papel fundamental na desconstrução do senso comum nacional de que mulheres seriam rivais, sentiriam inveja umas das outras e não conseguiriam apoiar-se mutuamente.

Outro aspecto extremamente significativo para este debate é a concepção de "matrifocalidade"2, conforme expresso por Cristina Stevens e Vânia Vasconcelos (2011). Intimamente ligado às relações de afetividade entre mulheres negras, verifica-se com frequência o conceito associado à "função maternal" das personagens, que se manifesta não apenas no exercício do cuidar dos seus, mas também no enfrentamento diário das situações difíceis, cercadas pelos conflitos acima mencio-

\footnotetext{
1 Apesar de a palavra "sororidade" não existir em língua portuguesa, uma palavra muito semelhante, "fraternidade", pode ser encontrada em qualquer dicionário descrita como "solidariedade de irmãos" ou, em sentido mais amplo, "harmonia entre os homens". Ambas as palavras vêm do latim, sendo sóror irmãs e frater irmãos, mas em nossa linguagem usual ficamos apenas com a versão masculina do termo; afinal de contas, a sociedade patriarcal ensina-nos que relações harmoniosas somente são possíveis entre homens.

2 Originalmente, refere-se às sociedades africanas em que, ao casar-se, o homem passa a pertencer à família de sua mulher, sem o exercício de dominação da mulher em relação ao homem.
} 
nados. Trata-se de uma herança africana não encontrada em nenhuma obra canônica, mas utilizada como pilar principal de muitos textos de autoria feminina afro-brasileira. A esse respeito, é notável a consideração de Stevens e Vasconcelos (2011, p. 75):

Representações

No caso da mulher afro-brasileira, precisamos ainda considerar a situação específica das imagens que o imaginário patriarcal/colonial projetou, a forma como isso se configurou na literatura, para então compreendermos o salto que significa o fato de as escritoras terem assumido a voz e a vez de personagens dessa vertente.

O fato é que nas representações literárias tradicionais, normalmente de autoria masculina, "a experiência da maternidade é represenda afetividade na literatura afro-brasileira de autoria feminina contemporânea tada frequentemente de forma estereotipada, quase sempre idealizada e sem considerar a complexidade psicológica e social que reveste essa experiência" (STEVENS; VASCONCELOS, 2011, p. 75). De acordo com a própria escritora Conceição Evaristo, "um aspecto a observar [na literatura brasileira] é a ausência de representação da mulher negra como mãe, matriz de uma família negra, perfil delineado para as mulheres brancas em geral" (EVARISTO, 2005a, p. 53).

O conceito de "matrifocalidade", portanto, irá auxiliar a pensarmos no exercício da maternidade e nas especificidades histórica das mulheres negras no Brasil. Conforme explicam Stevens e Vasconcelos (2011), trata-se de um conceito usado por muitos antropólogos para estudar a organização social das famílias negras das Américas, em que "a mãe é a figura estável e as outras pessoas do grupo doméstico funcionam ao seu redor; a maioria dos contatos dos membros da família é realizada com parentes matrilaterais, e as mulheres têm o poder de decidir sobre as crianças e a casa" (p. 75).

As autoras contam-nos ainda, a partir de Terezinha Bernardo (2003), que discute o papel das mulheres negras africanas com base em questões de religiosidade e gênero, que as mulheres iorubás exerciam liderança familiar e protagonismo no "espaço de trocas sociais, vale dizer, dos bens simbólicos, das negociações afetivas e comerciais, além de participarem dos conselhos supremos dos chefes urbanos, pelas sociedades que criaram"; “Já na diáspora, a história nos conta dessas africanas e suas dificuldades para criarem e manterem filhos em torno de si" (STEVENS; VASCONCELOS, 2011, p. 77). Por fim, é interessante 
perceber que, ao estudar o feminino em ação no campo religioso brasileiro, Bernardo (2003 apud STEVENS; VASCONCELOS, 2011) pesquisou outros grupos de mulheres não negras e entendeu que determinadas características desenvolvidas pelas afro-brasileiras diante de uma série de dificuldades peculiares ao seu cotidiano as faziam agir de maneira singular, autônomas, e com especial liderança.

Desse modo, é pertinente percebermos, com base nas noções acima discutidas, que as vivências compartilhadas pelas mulheres negras resultam num poder de fortalecimento das relações de afetividades, geRodrigo da ralmente expressas através de solidariedade, cooperação e cumplicidade Rosa Pereira entre os sujeitos femininos. A fim de investigar a representação das afetividades em perspectiva feminina afro-brasileira, tomaremos por base os 124 seguintes contos, publicados na série literária Cadernos Negros ${ }^{3}$ : "Beijo na face" (2003), "Olhos D’água" (2005b) e "Ayoluwa, a alegria do nosso povo" (2005) de Conceição Evaristo, bem como "Guarde segredo" (1998), "Ela está dormindo" (2001) e "A moça" (2011), de Esmeralda Ribeiro.

Neste primeiro momento, interessa-nos observar o modo como constroem-se as representações da afetividade a partir da valorização das mulheres negras enquanto sujeitos femininos, o que ocorre não só no que diz respeito às protagonistas, mas também a outras personagens femininas. $\mathrm{O}$ fundamental é que há sempre uma constante confluência de forças entre as mulheres que resulta no que podemos traduzir aqui por "sororidade", em conjunto com a "matrifocalidade" como pano de fundo das narrativas.

Em "Olhos d'água", a importância da afetividade feminina na caracterização da protagonista expressa-se através da sua relação com as figuras da mãe e da irmã. Será o afeto materno o principal fator de resistência diante da realidade de carência material que envolve a família da protagonista. Representada com grande sensibilidade poética, essa afetividade pode ser constatada, em especial, nas ocasiões em que, imersas às moléstias da fome, as filhas sentavam-se com a mãe na soleira $\mathrm{e}$ juntas ficavam contemplando as nuvens no céu: “A mãe, então, espichava o braço, que ia até o céu, colhia aquela nuvem, repartia em pedacinhos e enfiava rápido na boca de cada uma de nós. Tudo tinha de ser muito

3 A série Cadernos negros consiste em antologias literárias de contos e poemas de escritores afro-brasileiros contemporâneos. Editada de forma cooperativa e independente pelo grupo literário Quilombhoje, de São Paulo, é publicada ininterruptamente desde o ano de 1978, com periodicidade anual, mantendo-se fiel à proposta de alternar entre poemas e contos a cada edição. 
rápido, antes que a nuvem derretesse e com ela os nossos sonhos se esvanecessem também" (p. 31). Vemos que a falta de alimento é compensada pelo afeto materno, de modo que as filhas não se entregassem às injustiças da miséria e da fome. $\mathrm{Na}$ ausência de condições dignas, de alimento e mesmo de amparo social, a mãe utilizava-se da criatividade, recorrendo a brincadeiras para distrair e alegrar as filhas, transformando o "barraco" em espaço de fantasia: "E a nossa fome se distraía" (p. 31). Portanto, do ponto de vista das relações familiares, a afetividade da mãe para com as filhas funciona como forma de combate a condições sociais excludentes. Assim, a narrativa em primeira pessoa, desta filha já em idade adulta, uma mulher negra bem-sucedida, confirma que a afetividade materna, ao invés de dilacerar-se, cumpriu o papel crucial enquanto elemento de resistência frente à vulnerabilidade socioeconômica.

Representações da afetividade na literatura afro-brasileira de autoria feminina contemporânea

No mesmo conto, cumpre salientar também que a existência de todo um conjunto feminino, composto por gerações de mulheres negras, faz-se fundamental para a construção de uma espécie de cumplicidade entre iguais, considerando os aspectos matriarcais da cultura afrodescendente: “[...] eu nunca esquecera a minha mãe. Reconhecia a importância dela na minha vida, não só dela, mas de minhas tias e todas as mulheres de minha família. [...] Não, eu não esqueço essas senhoras, nossas Yabás ${ }^{4}$, donas de tantas sabedorias" (p. 32). O fato de colocar essas mulheres como fontes de conhecimento e fortalecimento não apenas as valoriza, mas rompe com a hegemonia do poder masculino de nossa sociedade patriarcal, essa tradicionalmente encontrada pela literatura brasileira. Mais do que sábias, as mulheres negras, conforme concebidas em "Olhos d'água", representam exemplos a serem seguidos: “[...] nossas ancestrais, que desde a África vinham arando a terra da vida com as suas próprias mãos, palavras e sangues” (p. 32).

Uma visão de mundo similar é reproduzida em "Ayoluwa, a alegria do nosso povo", mas em outro nível. Se em "Olhos d'água" a personagem expressa o seu apreço à ancestralidade, neste caso, tem-se a própria voz narrativa enquanto sujeito feminino que exerce a função de representar a comunidade, uma espécie de porta-voz ancestral e comunitária, responsável por perpetuar a tradição pelo contar da história.

4 Yabá (ou Iabá) significa Mãe Rainha, sendo o termo dado aos orixás femininos Yemanjá e Oxum; no Brasil, esse termo é utilizado para definir todos os orixás femininos em geral em vez do termo Obirinxá (Orixá feminino). o termo é dado a Yemanjá e Oxum, porque ambas estão intimamente ligadas da gestação ao parto e aos cuidados da mãe com o seu filho e também por terem sido rainhas. 
Isso não só valoriza o sujeito feminino negro, mas reverte a tradição em que os homens detêm o saber. Nesse sentido, quanto mais velhas mais sábias tornam-se tais mulheres, pelo acúmulo de experiências de vida.

Além disso, destaca-se o poder que a personagem de Ayoluwa carrega no nome, que simbolicamente significa "[...] aquela que veio para trazer a alegria para o nosso povo" (p. 39). Mesmo que não seja uma mulher ainda, mas uma criança recém-nascida, a menina representa um ser feminino negro que possui uma enorme significação para a sua comunidade, pois o seu nascimento muda a vida da comunidade: Rodrigo da "Quando a menina Ayoluwa, a alegria do nosso povo, nasceu, foi em boa Rosa Pereira hora para todos" (p. 35); "O seu inicial grito, comprovando que nascia viva, acordou todos nós. E a partir daí tudo mudou. Tomamos novamente a vida com as nossas mãos" (p. 39).

Em "Beijo na face", apesar de ser menos significativa, merece destaque o fato de que a protagonista, Salinda, uma mulher de meia idade, casada, com filhos, cuja vida encontra-se dividida entre o casamento em crise e a solidificação de um novo amor, recebe o apoio de outra personagem feminina: tia Vandu, "um misto de tia-avó, mãe e amiga" (p. 15), “[...] a única pessoa que adivinhou seu [de Salinda] sofrimento, acolheu seu segredo e se tornou cúmplice. [...] Tia Vandu era guardiã do novo e secreto amor de Salinda" (p. 14). Neste caso, a afetividade feminina revela-se pelo viés da cumplicidade, sem a qual as ações da protagonista supostamente não seriam levadas adiante. 0 resultado mais notável é a liberação da sexualidade, pois a nova situação amorosa da personagem revela-se homoafetiva, conforme pode-se interpretar no desfecho do conto: "[...] o nítido rosto da amiga surgiu para afirmar a força de um amor entre duas iguais. Mulheres, ambas [...] aves-fêmeas, ousadas mergulhadoras na própria profundeza" (p. 18). Assim, reforça-se por completo o caráter subversivo, do ponto de vista histórico-literário, das representações de afetividades em perspectiva feminina afro-brasileira.

Passaremos agora ao debate da figura materna enquanto papel exercido pelas personagens femininas de grande representatividade para refletirmos sobre a dinâmica do afeto na literatura afro-brasileira. Nos contos selecionados, todas as protagonistas adultas são mães e possuem uma forte relação afetiva com seus filhos. No caso de protagonismo infantil, a figura da mãe está sempre presente e é destacada por exercer função afetiva inestimável para com a filha. 
Nesse contexto, embora a protagonista de "Beijo na face" seja uma mulher-mãe com força de vontade, bem decidida e disposta a lutar pela guarda dos filhos, a representação talvez mais significativa da mulher enquanto mãe encontra-se em "Olhos d'água", em que a mãe tem um papel fundamental de afetividade para com as filhas, exercendo uma força extraordinária no enfrentamento das dificuldades inerentes a sua precariedade social. Com efeito, porém, o fator mais notável em relação à figura da mulher-mãe em "Olhos d'água" é a mãe da protagonista, associada à "mamãe Oxum". o próprio título do conto faz referência às "lágrimas e lágrimas, [...] prantos e prantos" (p. 32) que a mãe da protagonista "trazia, serenamente em si, águas correntezas. [...] Águas de mamãe Oxum!" (p. 33). Vale destacar que, segundo a mitologia africana, Mamãe Oxum é a deusa da fertilidade na Terra, sendo a água Representações da afetividade naliteratura afro-brasileira de autoria feminina contemporânea seu elemento. Assim, representa a ligação entre mães e filhas, mas, não só entre elas, também a sua relação com a tradição afrodescendente. Nessa mesma linha, o conto "Ayoluwa, a alegria do nosso povo" traz uma valorização da mãe da protagonista, associada à fertilidade, pois, ao anunciar a gravidez, reestabelecerá a esperança do futuro melhor na comunidade: “[...] não houve quem não fosse fecundado pela esperança [...]. Toda a comunidade, [...] todos se engravidaram da criança nossa, do ser que ia chegar" (p. 38).

Tais representações femininas, diretamente ligadas à questão das afetividades, podem ser vistas como resposta à visão estereotipada da mulher negra na literatura brasileira tradicional que lhe nega a fertilidade e, consequentemente, enquanto figura materna. As personagens femininas negras nos contos selecionados podem ser consideradas como representantes da fertilidade feminina afrodescendente, a qual Eduardo de Assis Duarte (2006) aponta como, até então, ausente na literatura brasileira para as personagens femininas negras, antes da produção literária afro-brasileira de autoria feminina.

Desse modo, reforçamos a perspectiva das afetividades positivas e saudáveis que perpassa a produção literária de autoria feminina afro-brasileira. Verificamos a força dessas mulheres afrodescendentes nas origens ancestrais e nas gerações futuras, pois espelham-se mães e filhas, umas nas outras em busca de suas raízes. Revelamos, ainda, que no universo brasileiro de origem africana, as mulheres negras são sujeitos que possuem valor inestimável e existe um reconhecimento afetivo entre elas. Infelizmente, a tradição literária brasileira foi responsável 
pelo apagamento sistemático da importância histórica dos sujeitos afro-brasileiros, contexto em que as mulheres negras particularmente sofreram dupla discriminação: racial e de gênero.

\section{A dimensão da espiritualidade afrodescendente na con- solidação das afetividades}

A dimensão espiritual da cultura afro-brasileira pode também ser vista como intimamente ligada à questão das afetividades. Apresenta-se interessante, nesse sentido, o conto "Guarde segredo", cuja trama dialo-

Rodrigo da Rosa Pereira ga intertextualmente com o romance Clara dos Anjos, de Lima Barreto, conferindo um final subversivo que ao tempo do romance não teria sido possível. A partir de uma presença ancestral do escritor Lima Barreto, o qual possui uma misteriosa relação de amizade com a avó da protagonista, essa age com resistência e termina por reverter o papel que o "destino" reservava-lhe. Clara liberta-se do comportamento comumente reproduzido diante das questões de discriminação étnico-racial, de gênero e de classe social, sendo tal capacidade promovida de algum modo em estreita relação com o poder espiritual afro-brasileiro. Ela não aceita com resignação o fato de ser desvirginada e traída por Cassi Jones, não o deixando sair impune de seus atos. Do contrário, ela seria mais uma vítima que deveria aceitar ter sido usada apenas como objeto de diversão (sexual) do rapaz.

Paralelamente a essa força espiritual, é crucial perceber a afetividade da avó - personagem feminina - tornar-se o elemento central a exercer influência na vida da protagonista, acolhendo e acompanhando todos os atos da neta. Ao final do conto, por exemplo, é a avó quem orienta a neta esconder a arma do crime (na jabuticabeira do quintal) e fugir, sendo atendida com prontidão. Além disso, a avó é retratada como misteriosa e supostamente onisciente em relação aos acontecimentos na vida de Clara, sendo uma personagem cuja presença, por vezes, sugere-se mais espiritual do que física. A avó pode ser vista como uma espécie de guia espiritual para Clara, assim como Lima Barreto.

A força da espiritualidade afro-brasileira está presente também em "Ela está dormindo", em que temos um caso um tanto diferente, mas não menos significativo: a protagonista, que se encontra em depressão, encontra auxílio junto a um grupo de mulheres negras, mantido por Mãe Rocecaju, uma mãe de santo que, como tal, é representante significati- 
va das crenças e práticas religiosas advindas da África. Enquanto gestora do grupo, essa personagem feminina desempenha um papel simbólico de compartilhamento da herança cultural afro-brasileira, relevante no que diz respeito tanto à religiosidade quanto às relações de gênero.

Cabe aqui um parêntese para explorarmos o conceito "mãe de santo". Segundo Agnes Mariano (2007), esse título é conferido à mulher que, nos cultos afro-brasileiros, administra o terreiro (comunidade religiosa) e dirige os cultos aos orixás. Tal papel tem origem no Candomblé, na Bahia do século XIX, e expressa o misto de liderança religiosa, chefia política e poder terapêutico que exercem as mulheres que, com diplomacia, inteligência e fé, reúnem os elementos necessários para garantir ânimo e autoestima a um terreiro ${ }^{5}$. Para a nossa análise, o fator mais significativo é que, segundo Mariano (2007), a tarefa das mães de santo, Representações da afetividade naliteratura afro-brasileira de autoria feminina contemporânea repleta de responsabilidades e sacrifícios, quando desempenhada com competência, traz a possibilidade de mudar a realidade das pessoas que as cercam. É nesse viés que a personagem não apenas age no sentido específico de proporcionar o caminho para a resolução do problema de Flor, como uma luz em meio à crise de relacionamento da protagonista, mas também tem um papel de importância coletiva, pois é responsável pela criação e manutenção de um grupo de autoajuda a mulheres negras.

Portanto, é interessante perceber que são as palavras de Mãe Rocecaju que incentivam a protagonista a encarar a realidade e obter o reconhecimento de que o problema de Flor era de ordem psicológica, não espiritual, demonstra a sabedoria dessa figura na sociedade contemporânea: "Cuide-se, desafie a sua depressão, vença essa doença e no seu caso você precisa da ajuda de um psicólogo e de uma terapeuta. Filha, os espíritos somente podem dar-lhe proteção espiritual" (p. 34). Embora o conflito psicológico da protagonista não seja resolvido, ele é ao menos amenizado a partir da relação de afetividade proporcionada pelo "Grupo 'Sele' de Autoajuda à Mulher Negra mantido pela mãe de santo" (p. 34).

5 Cumpre ressaltar que, segundo Mariano (2007), a liderança feminina nesta tradição religiosa explica-se pelo fato de que as pioneiras do Candomblé eram princesas africanas que vieram para a Bahia em fins do século XVIII e que criaram o princípio de que as suas casas religiosas só poderiam ser lideradas por mulheres, uma tradição mantida até hoje nos terreiros mais antigos. Na África, as mulheres iorubás participavam do conselho dos ministros, tinham organizações próprias e chegaram a liderar um intenso comércio que incluía rotas internacionais. Foi por isso que, na Bahia do início do século XIX, elas conseguiram o que parecia impossível: deram à luz uma organização religiosa que conciliava tradições de diferentes povos, resistindo à miséria da escravidão e à perseguição policial. 
Vale ainda pensar na relação afetividade estabelecida a partir do relacionamento de Flor com as outras mulheres do grupo, tendo o indicativo da vivência comunitária enquanto outro elemento fundamental da espiritualidade afrodescendente. Conforme observa Antônio Aparecido da Silva (2007), ao debruçar-se sobre a espiritualidade dos povos bantos, quem vive comunitariamente mantém-se em permanente união e daí recebe os benefícios; ao contrário, quem não vive comunitariamente determina a sua própria maldição. Assim, o que assegura o viver com dignidade seria a vivência comunitária, que não suprime o valor do Rodrigo da indivíduo, descambando em coletivismo, mas o qualifica como ser de Rosa Pereira relações, sendo tal vivência o salvo-conduto para a vida eterna, para a própria condição de ancestral.

Nesse sentido, a vivência comunitária proporcionada pelo Grupo Sele aponta também para a construção de afetividades femininas como mais uma forma de representação da força da espiritualidade afro-brasileira. É justamente no contato com as mulheres do grupo de autoajuda que Flor ganha consciência da sua condição fragilizada. Ainda que, conforme mencionado, a protagonista não consiga vencer a sua depressão, nem se livrar do namorado usurpador, a vivência coletiva estabelece uma relação de solidariedade e união. Logo, são justamente as relações entre espiritualidade afro-brasileira, solidariedade, cooperação e cumplicidade femininas que irão demarcar as dinâmicas afetivas das personagens femininas. Cumpre ressaltar que essa espécie de beneficiamento mútuo entre as personagens femininas reforça a noção de "sororidade", ao passo que o próprio espaço dessas relações não apenas é impulsionado, mas de fato somente faz-se possível pela existência da mãe de santo, ou seja, mais um caso simbólico que valoriza a "matrifocalidade". É por essa razão que tais componentes devem ser considerados centrais na caracterização das afetividades na literatura afro-brasileira de autoria feminina.

Outra reflexão cabível diz respeito à noção de terreiro enquanto espaço integrador, capaz de promover relações de afetividades positivas e saudáveis. Na concepção de Mariano (2007), todo terreiro é, em princípio, uma família, porque é uma família espiritual. Como elo maior que une a todos, no terreiro, há uma busca de contato com os elementos que nutrem a vida de todos os seres vivos: a força dos ventos, do fogo, das matas, da terra, das pedras, das águas (os orixás são simbolizados pelas forças naturais). Mas outros aspectos da vida também são contemplados na comunidade religiosa: apoio financeiro, moradia, criação de escolas, bibliotecas, museus, 
grupos de estudo, cursos profissionalizantes, assistência à saúde. Assim, aqueles que exercitam os seus direitos e deveres para com a comunidade podem considerar-se membros de uma família e, de fato, filhos e irmãos de santo. Para Nei Lopes (2004), o papel social do terreiro é agir como um veículo e um elo entre a diáspora africana e seus ancestrais, biológicos ou míticos, próximos ou divinizados. Isso, ao mesmo tempo, procura assegurar com oferendas, sacrifícios e festas a comunicação entre os dois níveis da existência e a realização, por seus integrantes, do tão desejado trinômio paz-saúde-prosperidade. Portanto, não somente o Grupo Sele do conto possa ser associado a um terreiro, mas a própria literatura afro-brasileira possivelmente exerça um papel de natureza similar.

\section{Afetividades dilaceradas: a configuração de vulnerabilida- des a partir do afastamento da tradição afrodescendente}

Representações da afetividade na literatura afro-brasileira de autoria feminina contemporânea

Outro viés para pensar as representações da afetividade dá-se pelo entrelaçamento da dimensão espiritual afrodescendente com as diversas situações de vulnerabilidades das personagens. Em diversos contos, é possível verificar uma estreita relação do dilaceramento de afetividades como resultante do distanciamento das personagens em relação às tradições afro-brasileiras. Ou seja, não estamos diante de protagonistas negras que vivenciam a tradição afrodescendente enquanto herança ancestral; pelo contrário, são personagens em condições degradantes justamente em função do afastamento das crenças tradicionais de origem africana. Se as representações de vulnerabilidades afetivas demonstram-se consequências negativas do afastamento da tradição, com efeito, as narrativas em questão irão representar um universo de mulheres fragilizadas cuja degradação psicológica, moral e geralmente física encontra-se associada às condições espirituais, não apenas socioeconômicas.

Para explorar essa perspectiva, trataremos do conto "A moça", em que temos uma protagonista que acaba embarcando num processo de fragilização espiritual e profunda decadência material, física e mental justamente por não compartilhar das crenças e prática religiosas de matriz afrodescendente. Inicialmente, ao firmar um relacionamento sério com um homem que lhe fornecia todas as mordomias, ela deixa de exercer a prostituição e ganha o seu próprio apartamento. Porém, mesmo com boas condições de vida, ao final do conto, pouco tempo depois da morte do companheiro, ela embarca num processo de decadência física e mental. 
Como resultado do afastamento da tradição, o elemento fundamental da decadência da protagonista é o fato de ignorar a sua proteção espiritual, uma "entidade" ligada à religiosidade afro-brasileira, representada como a "moça' que morava dentro" dela, pois "uma vizinha adepta ao candomblé" incumbiu-se, certa vez, "de passar um recado da entidade" (p. 76). De acordo com a entidade, a protagonista deveria seguir “o exemplo de outras mulheres que tratavam suas 'moças' com a devida atenção; eram mulheres discretas, trabalhadoras, prósperas e tinham bons relacionamentos amorosos" (p. 76). Por tratar-se da reliRodrigo da gião candomblé, supostamente, a entidade configura-se em Orixá femiRosa Pereira nino que estava disposta a dar-lhe a devida proteção espiritual, desde que "cuidasse dela com oferendas e todos os rituais sagrados" para que trouxesse "boas coisas pra sua vida", sendo que "a falta de atenção com os seus protetores espirituais pode causar sérios problemas" (p. 76).

0 recado que recebe da entidade coloca-se como uma espécie de chamado à cultura espiritual afrodescendente, porém, é ignorado. À medida que a Orixá não recebe a devida atenção por parte da protagonista, essa se torna espiritualmente vulnerável. Ocorre que a protagonista não dera atenção para o recado simplesmente por não acreditar nisso, reiterando a sua condição de distanciamento da tradição. Assim, a falta de crença e atenção da protagonista na religiosidade afro-brasileira leva-a a sofrer o alto custo do desrespeito à tradição: perde o marido e é perseguida pelo espírito dele pelo resto da vida, o qual lhe impede de ter sucesso nas suas ações. No entanto, a alienação da protagonista em relação à tradição afro-brasileira é tamanha, ao ponto de que "A mente da jovem não conseguia ligar um fato com o outro, sua vida antes e depois [...]” (p. 79).

É preciso considerar que o espírito do ex-marido representa uma presença espiritual nociva que poderia ser expulsa por um agente de proteção espiritual, sendo necessário apenas que a protagonista se dedicasse às práticas religiosas afro-brasileiras. Tal perspectiva vai ao encontro do que Silva (2007) descreve sobre a vivência espiritual: que toda pessoa tem um Orixá que zela por ela e que a vida espiritual mediada pelos Orixás é um fator de equilíbrio para as pessoas. Um dos pontos mais pertinentes para a reflexão é que ainda que a representação do poder espiritual no conto exerça força em sentido oposto daquele presente em "Guarde segredo", sendo uma positiva e outra negativa, o que interessa-nos perceber é capacidade de intervenção nas ações dos vivos e influência das dinâmicas afetivas nas tramas. 
É importante levarmos em conta que tal distanciamento não se apresenta como uma ação intencional; muito pelo contrário, as personagens tornam-se vítimas das circunstâncias. De acordo com Renato Ortiz (1978), com a consolidação do movimento de urbanização e industrialização, principalmente a partir dos anos 1930, marcando o fim de uma sociedade que baseava sua produção no trabalho agrícola, observamos uma desagregação da memória coletiva negra, conforme as religiões afro-brasileiras readaptam-se ao novo sistema. Para ascender na estrutura social, os negros não veem alternativa senão aceitar os valores impostos pelo mundo branco, recusando assim tudo aquilo que tem uma forte conotação afro-brasileira. Segundo o autor, existia um desejo de "embranquecimento" que corresponde a um complexo de inferioridade do negro diante do branco, decorrente da posição inferior do negro no sistema escravocrata brasileiro. Concomitantemente, verificamos a união de negros e portugueses devido à miséria de classe, ou seja, a favela torna-se o lugar onde agrupa-se uma classe marginal à sociedade. A religião e as práticas afro-brasileiras tornam-se, para muitos, o único consolo.

Ainda de acordo com Ortiz, a desagregação da memória coletiva negra ocorre no interior dos próprios cultos afro-brasileiros, particularmente nas nações bantos, pois essa etnia tende a sincretizar, com maior facilidade, suas crenças. Assim, na medida em que o negro integra-se à nova sociedade brasileira, o movimento de desagregação acentua-se e a integração na sociedade o leva, senão à renúncia da tradição, ao menos à reinterpretação dessa segundo novos valores sociais. Neste sentido, os contos em questão colocam-se, por um lado, enquanto "denúncia" daquela realidade e, por outro, como movimento de resistência, representando uma corrente literária que busca preservar o mundo simbólico afro-brasileiro.

\section{Considerações finais}

Longe de encerrar o debate, cumpre uma reflexão conclusiva. De modo geral, compreendemos a literatura afro-brasileira de autoria feminina como aquela que institui uma reflexão a partir da experiência de um estar no mundo diferenciado, indicado pelas identidades de gênero e etnia. Se ainda hoje são constatáveis muitas das construções estereotípicas sobre as mulheres negras, há de ressaltar-se que na contracorrente desse discurso surgem as produções literárias afro-brasileiras, especialmente as de autoria feminina. 
Ao contrário das obras canônicas, em que encontramos perspectivas estereotipadas das pessoas negras, especialmente as mulheres, nas escritoras afro-brasileiras verificamos a existência de uma preocupação com a representação positiva da afetividade das personagens femininas negras, que em muito contrastam com as representações tradicionais. Por fim, ao mesmo tempo em que o distanciamento da tradição pode ser visto como o grande fator responsável pelos conflitos afetivos, por outro lado, podemos inferir das narrativas a importância do resgate cultural e identitário como a

Rodrigo da forma de reconstrução da afetividade, intimamente ligada à ideia de Rosa Pereira comunidade ou coletividade.

\section{REFERÊNCIAS}

BERNARDO, T. Negras, mulheres e mães: lembranças de Olga de Alaketu. São Paulo; Rio de Janeiro: EDUC; PALLAS, 2003.

DUARTE, E. de A. Memória e ficção na narrativa feminina afro-brasileira. In: MONTEIRO, M. C.; LIMA, T. M. de O. (Orgs.). Entre o estético e o político: a mulher nas literaturas clássicas e vernáculas. v. 1. Florianópolis: Editora Mulheres, 2006. p. 227-232.

Por um conceito de literatura afro-brasileira. In: FONSECA, M. N. S. (Org.). Literatura e afrodescendência no Brasil: antologia crítica. v. 4. Belo Horizonte: UFMG, 2011. p. 375-403.

EVARISTO, C. Beijo na face. In: BARSOSA, M.; RIBEIRO, E. (Orgs.). Cadernos negros: contos afro-brasileiros. v. 26. São Paulo: Quilombhoje, 2003. p. 11-18.

Ayoluwa, a alegria do nosso povo. In: BARSOSA, M.; RIBEIRO, E. (Orgs.). Cadernos negros: contos afro-brasileiros. v. 28. São Paulo: Quilombhoje, 2005. p. 35-39.

. Gênero e etnia: uma escre(vivência) de dupla face. In: MOREIRA; N. M. de B.; SCHNEIDER, L. (Org.) Mulheres no mundo: etnia, marginalidade e diáspora. João Pessoa: Ideia, 2005a. p. 201-212. 
- Olhos d'água. In: BARSOSA, M.; RIBEIRO, E. (Orgs.). Cadernos

negros: contos afro-brasileiros. v. 28. São Paulo: Quilombhoje, 2005b. p. 29-33.

LOPES, N. Enciclopédia brasileira da diáspora africana. São Paulo: Selo Negro, 2004.

MARIANO, A. Mães de santo. Histórias do povo negro. 8 nov. 2007. Disponível em: <https://historiasdopovonegro.wordpress.com/2007/11/08/ maes-de-santo/>. Acesso em: 8 mar. 2018.

Representações da afetividade naliteratura afro-brasileira de autoria feminina contemporânea

ORTIZ, R. A morte branca do feiticeiro negro. Petrópolis, Brasil: Editora Vozes, 1978.

RIBEIRO, E. Guarde segredo. In: QUILOMBHOJE (Org.). Cadernos negros: os melhores contos. São Paulo: Quilombhoje; Fundo Nacional da Cultura, Ministério da Cultura, 1998. p. 65-72.

Ela está dormindo. In: BARSOSA, M.; RIBEIRO, E. (Orgs.). Cadernos negros: contos afro-brasileiros. v. 24. São Paulo: Quilombhoje, 2001. p. 33-40.

Mulheres nos espelhos. In: BARSOSA, M.; RIBEIRO, E. (Orgs.). Cadernos negros: contos afro-brasileiros. v. 26. São Paulo: Quilombhoje, 2003. p. 49-55.

A moça. In: BARSOSA, M.; RIBEIRO, E. (Orgs.). Cadernos negros: contos afro-brasileiros. v. 34. São Paulo: Quilombhoje, 2011. p. 75-80.

SILVA, A. A. da. Brasil: espiritualidade afro. Revista Missões. n. 9, nov. 2007. Disponível em: <http://www.adital.com.br/?n=74f>. Acesso em: 8 mar. 2018.

STEVENS, C.; VASCONCELOS, V. Mães de outras cores: matrifocalidade na literatura afro-brasileira de autoria feminina. Cerrados, Brasília, v. 20, n. 32, p. 69-86, 2011. Disponível em: <http://periodicos.unb.br/ index.php/cerrados/article/view/8401/6397>. Acesso em: 27 jul. 2018. 
VASCONCELOS, V. No colo das Iabás: maternidade, raça e gênero em escritoras afro-brasileiras. Tese (Doutorado em Literatura e Práticas Sociais) - Programa de Pós-Graduação em Literatura, Universidade de Brasília, Brasília, 2014.

Recebido em fevereiro de 2018

Aceito em abril de 2018

Rodrigo da

Rosa Pereira

136 